\title{
O planejamento de CAMPI UNIVERSITÁRIOS COMO PRÁTICA PARTICIPATIVA E EDUCATIVA
}

\author{
Carlos Roberto Monteiro de Andrade \\ ALESSANDRA PAVESI
}

R E S U M O Neste trabalho, são discutidas duas experiências de planejamento de campi universitários norte-americanos que tiveram como principal pressuposto a participação ativa da comunidade acadêmica: "The Oregon Experiment", promovido pela Universidade de Oregon na década de 1970, e o projeto do Lewis Center for Environmental Studies no College de Oberlin (Ohio), realizado vinte anos depois, em uma década já fortemente marcada pela emergência da questão ambiental. Não obstante as duas experiências tenham se orientado por distintas teorias e principios de planejamento historicamente situados, no artigo procura-se evidenciar o conteúdo comum a ambas, que remete ao entendimento da participação como práxis e do campus como um laboratório ideal para a sua realização.

P A L A V R A S - C H A V E Planejamento; campus; participação; educação; sustentabilidade.

\section{INTRODUÇÃO}

A universidade surge nas cidades medievais europeias que despontavam no chamado renascimento urbano iniciado em meados do século XI - a de Bolonha em 1088, a de Paris em 1150, a de Oxford em 1167 (primeira cidade universitária). No interior das cidades a universidade delimitou seu território particular, transformou o uso de edifícios pré-existentes, construiu edifícios especializados, conferiu identidade às zonas ou bairros da cidade, como o "Quartier Latin", em Paris - embora, como bem observou Thomas Bender (1988, p. 290), "as relações entre as duas são necessariamente tensas, e elas não podem ser assimiladas uma à outra”.

O campus como modelo de implantação de instituições de educação superior nasceu no final do século XVIII com a fundação das primeiras universidades americanas, mas após a Segunda Guerra difundiu-se em outros países, inclusive da América Latina.

Não obstante projetos para cidades universitárias já viessem sendo realizados no Brasil desde os anos 1930, ${ }^{1}$ neste país o modelo americano do campus foi introduzido nas décadas de 1950 e 1960, período no qual as tendências da modernização brasileira assimilavam os paradigmas ditados pelos Estados Unidos, tanto em matéria de educação, como de organização dos espaços para a sua prática.

Foi a partir do início dos anos 1960 que o planejamento de campi, já fortemente influenciado pelas vertentes teóricas e as práticas dominantes de planejamento e desenho urbano, seria progressivamente depurado de conteúdos sociais e pedagógicos, passando a

1 Como aqueles dos arquitetos Le Corbusier e Marcelo Piacentini, ambos de 1936 ou o da Universidade de São Paulo, na Capital do Estado de mesmo nome, em meados dos anos 1940 . 
20 termo ambientalização inspira-se no inglês "greening" e refere-se, mais amplamente, à inserção da dimensão ambiental e dos preceitos da sustentabilidade nas instituições e práticas culturais da sociedade moderna. Transposto para a educação superior, indica os princípios e procedimentos adotados pelas instituições de ensino para adequar suas políticas e atividades às metas de conservação ambiental e da justiça social. ser regido por uma racionalidade técnica consubstanciada em cálculos, na adequação de meios e fins, nos conceitos de eficiência e otimização, em detrimento de considerações éticas e da participação da comunidade no debate sobre os valores que deveriam orientar o desenvolvimento físico da instituição.

No Brasil, esse fenômeno agravou-se em consequência do golpe militar, com o qual se instaurou uma nova abordagem dos problemas da universidade, marcada pela "paulatina e decisiva transformação de questões políticas em questões técnicas” (Bomeny, s.d.). A própria reforma universitária, empreendida no momento mais duro da ditadura, foi levada a efeito por técnicos, não obstante tenha sido precedida pela ampla mobilização da comunidade acadêmica. $\mathrm{O}$ planejamento do espaço físico não fugiu a essa determinação: entre os anos 1960-70, Atcon, técnico da equipe de consultores da United States Agency for International Development (USAID), propunha, em seu Manual de planejamento integral de campi, um modelo único de ordenamento espacial, que serviu como referência na implantação de inúmeras universidades.

$\mathrm{Na}$ década de 1970, assistiu-se no Brasil a grandes investimentos em instalações universitárias, cuja realização em tempos curtos favoreceu as práticas da reprodução de projetos e da repetição de elementos construtivos, para promover economias de escala e facilitar as obras (Macedo, 1986a). A ênfase em sistemas de racionalização da construção e a centralização das decisões de projeto, induzida também pelo ritmo acelerado de sua realização, teriam determinado a exclusão de consideraçóes referentes à qualidade dos espaços, às necessidades de seus futuros ocupantes e a conteúdos locais e individualizados (Id., 1986b).

O legado desta época estende-se até o momento atual, embora a abertura democrática tenha favorecido a descentralização das decisões, com a criação de órgãos colegiados que compreendem representantes dos diversos setores da comunidade. De fato, até mesmo nestas instâncias tende-se a privilegiar os argumentos técnicos, desqualificando-se eventuais críticas e outras proposições e discursos. É como se a técnica pairasse acima de perspectivas, interesses e projetos conflitantes, e com isso escapasse à esfera da política, quando é possível averiguar que, ao contrário, qualquer solução técnica - inclusive aquelas ideadas para mitigar e reverter os processos de degradação ambiental - pressupõe determinados modelos de sociedade e produz efeitos diferenciados nos diversos âmbitos espaciais e perspectivas temporais, recaindo, portanto, necessariamente no domínio das decisões políticas.

A incorporação da questão ambiental nas operações de planejamento e gestão do território universitário - recomendada nos inúmeros tratados que preveem a ambientalização ${ }^{2}$ da educação superior (Wright, 2002; Fouto, 2002; Pavesi e Freitas, 2008) - passa por esse questionamento, na medida em que vem sendo interpretada mais como uma demanda por ações "substantivas" (pontuais e paliativas) caracterizadas por certa fixidez (programas de gestão de resíduos e economia de recursos e energia), do que como uma necessidade de questionar em profundidade a atual missão, organização, dinâmica e práticas das instituições de educação superior, diante das limitações impostas pelas realidades biofísicas nas quais se inserem.

O efeito dessa visão é que, muito embora centenas de instituições tenham se disposto, no mínimo em sua retórica, a redirecionar as próprias atividades para uma condição de "sustentabilidade", seus esforços - coordenados em geral por órgãos ou comissōes especializadas - dificilmente envolvem a comunidade universitária como um todo. Nem contribuem, portanto, para trazer à tona e equacionar os conflitos pela ocupação do solo e o uso de recursos naturais, que aqui como em outros contextos tendem a culminar em 
impactos ambientais por vezes irreversíveis (invasões e degradação de áreas naturais protegidas, depauperação da base de recursos ambientais, destruição da paisagem etc.).

A ideia de sustentabilidade expressa nessa tendência dominante negligencia a natureza multidimensional deste constructo, ${ }^{3}$ que Ignacy Sachs, um de seus principais precursores, preocupou-se em explicitar justamente para dissipar os "mal-entendidos semânticos" que estariam na origem das disputas em torno do papel da tecnologia e do mercado no redirecionamento do desenvolvimento socioeconômico. Ao privilegiar medidas substantivas e técnicas em detrimento de um debate mais amplo sobre as próprias responsabilidades na definição e no equacionamento da problemática ambiental, as instituições de educação superior estariam, assim, escamoteando, a um só tempo, a dimensão cultural da sustentabilidade e sua qualidade controversa e, portanto, necessariamente política. Mas, sobretudo, ao apropriar-se do conceito de sustentabilidade para responder a objetivos (e favorecer interesses) restritos, a universidade deixa de cumprir sua função principal, que consiste em propiciar um ambiente de aprendizagem social ativa (Glasser, 2007).

Para Campbell (1996), a sustentabilidade torna-se princípio organizador de processos de aprendizagem social somente se for incorporada à compreensão das controvérsias e dos conflitos inerentes à sociedade industrial - notadamente entre as metas do crescimento econômico, da proteção ambiental e da justiça social - em suas expressões concretas. Essa visão abre novas perspectivas de intervenção, cujo êxito depende de competências e instrumentos para esclarecer a natureza dos conflitos com o propósito de gerenciá-los. Assim, os procedimentos organizacionais, tais como o debate político e a negociação - que pressupõem a busca por uma linguagem compartilhada - adquirem igual ou maior importância que as ações substantivas, podendo, inclusive, ampliar e inovar o repertório destas últimas mediante o aporte dos conhecimentos dos sujeitos/grupos envolvidos.

$\mathrm{Na}$ experiência de Orr (2006), mentor do projeto para o Lewis Center for Environmental Studies, a incorporação das funções e do valor intrínseco dos sistemas ecológicos no planejamento e no projeto dos edifícios em campi universitários torna-se mais efetiva na medida em que se encoraja a participação, se valorizam a iniciativa e as novas ideias, e se aceitam os riscos associados ao processo de adaptação das organizações a realidades ecológicas mais abrangentes:

O projeto ecológico [...] funciona melhor quando as pessoas compartilham uma visão comum e compreendem aquilo que se propõem a fazer em um contexto ecológico, moral e histórico mais amplo. Portanto, isso requer mais que a expertise limitada dos administradores, e sim uma cultura na qual as pessoas se disponham a ler sobre os mais diversos temas e casos, a pensar com imaginação, a desafiar crenças, a considerar questôes maiores que aquelas que dizem respeito à sobrevivência das instituições. Em breve, o projeto ecológico tem êxito quando as pessoas têm prazer em trabalhar juntas, energizadas por uma visão poderosa (p. 162).

A própria ideia de "projeto ecológico", que Orr desenvolve em dois capítulos introdutórios ao relato da experiência realizada no College de Oberlin, encontra-se imbuída de significado cultural e epistemológico: "a revolução do projeto ecológico não consiste apenas em otimizar o uso de energia e materiais, [...] mas em uma visão mais profunda e coerente do lugar do ser humano na natureza" (ibid., p. 36). Em outras palavras, o projeto ecológico propõe subverter a concepção de natureza como entidade antagônica à sociedade (e à cidade), para reintegrar os seres humanos na chamada "teia da vida" (Capra, 1996).
3 Segundo Sachs (1994), a sustentabilidade desdobra-se em cinco dimensões complementares: a sustentabilidade social, que se fundamenta na equidade e na distribuição da renda e dos bens; a sustentabilidade econômica, que requer a alocação e o gerenciamento mais eficiente dos recursos sendo que a eficiência econômica deve ser avaliada em termos macrossociais e não apenas com base no critério da rentabilidade empresarial; a sustentabilidade ecológica, que se fundamenta no incremento do potencial de uso dos recursos e, simultaneamente, na proteção dos sistemas de sustentação da vida; na redução do consumo de combustíveis fósseis e recursos não renováveis e em sua substituição por recursos renováveis; na redução do volume de resíduos e poluentes; na autolimitação no consumo de bens materiais e matérias primas; na produção de tecnologias de baixo impacto ambiental; na definição de normas e na criação de instrumentos econômicos, legais e administrativos; a sustentabilidade espacial, que demanda uma configuração rural-urbano mais equilibrada e uma meIhor distribuição territorial dos assentamentos humanos e das atividades econômicas, com ênfase na redução da concentração em áreas urbanas/metropolitanas; na proteção ou recuperação dos ecossistemas frágeis; na produção agrícola e florestal de caráter regenerativo, na agricultura familiar, no acesso ao crédito e ao mercado para os pequenos agricultores e na criação de reservas naturais para proteger a biodiversidade; e, finalmente, a sustentabilidade cultural, que implica a busca das raízes endógenas de processos de modernização e de sistemas agrícolas integrados, processos que promovam mudanças, porém dentro da continuidade cultural e que traduzam 0 conceito de "ecodesenvolvimento" em um conjunto de soluções específicas para o local, o ecossistema, a cultura e o território. 
Tal desafio e as condições que seu enfrentamento implica dificilmente se realizam quando as decisões sobre o projeto dos edifícios, das paisagens, dos processos de conversão de energia e materiais são prerrogativas exclusivas de administradores e especialistas (notadamente engenheiros e arquitetos), especialmente em circunstâncias nas quais: inexistem políticas que disponham sobre a incorporação da questão ambiental nos objetivos e nas metas e práticas institucionais; as inovações esbarram em padrões de organização e dinâmicas sociais historicamente consolidadas, bem como no desinteresse e na relutância dos profissionais em questionar e transformar as próprias competências e práticas; e por fim, na falta de comunicação entre as esferas da produção de conhecimento e da gestão.

De fato, se a indissociabilidade entre ensino, pesquisa e extensão é considerada "premissa de direito", sendo inclusive prevista pela Constituição Federal do Brasil (Art. 207), as atividades de planejamento e gestão dos campi universitários não são, em geral, reconhecidas como práticas indissociáveis das outras. No entanto, o ambiente do campus universitário, que compreende o espaço físico e a infraestrutura de suporte para as múltiplas atividades sociais, culturais, políticas e acadêmicas que nele se desenvolvem e das quais participa também a comunidade local, proporciona as mais diversas oportunidades de aprendizagem, configurando parte daquilo que se entende por currículo oculto, cuja força reside justamente na produção de atitudes, afetos, formação de subjetividades, valores e componentes cognitivos, mediante as práticas e as mensagens implícitas de que se constitui (Silva, 1992). Por sua vez, o planejamento e a gestão ambiental do campus universitário - entendidos como práticas consolidadas, em seus procedimentos e ferramentas, para garantir a preservação ou restauração da qualidade ambiental (Souza, 2000) - ao mesmo tempo em que podem tornar-se um espaço discricionário para o exercício e a verificação de competências não apenas interpretativas da realidade, mas também de intervenção sobre ela, oferecem a possibilidade de articular a teoria com a prática, os saberes com a ação, o conhecimento com a ética. Portanto, as potencialidades educativas que encerram o ambiente "natural" (áreas verdes e protegidas) e construído (edificaçôes e infraestrutura) do campus bastaria para justificar a inclusão de seu planejamento/gestão entre as práticas cuja indissociabilidade é prevista por lei, bem como entre as preocupaçôes e os objetos das diretrizes e disposições das políticas institucionais.

Este trabalho se propõe a analisar duas experiências participativas de planejamento e projeto em campi universitários americanos. O "Experimento de Oregon", empreendido pela Universidade de Oregon na década de 1970 destaca-se pelo pioneirismo da instituição na inovação radical do modo de produzir o espaço físico do campus. Já o projeto para o edifício sustentável do Lewis Center for Environmental Studies (College de Oberlin) chama a atenção pela tenacidade de um pequeno grupo de docentes, estudantes e profissionais para superar as resistências opostas pela própria instituição.

Ambas as experiências deram origem a publicaçôes, cuja leitura crítica nos permitiu compreender os aportes de cada proposta para uma cultura do planejamento/projeto participativo de campi universitários. Importa também considerar que tais propostas devem ser situadas e avaliadas em seus contextos históricos específicos e bastante distintos. Assim, não se trata de compararmos duas experiências significativas de planejamento de campi universitários, sem levar em conta as particularidades de cada uma delas dos pontos de vista socioeconômico e político-cultural, mas sim de as situarmos em relação às agendas ideológicas e teóricas, no que se refere ao planejamento físico dos territórios universitários, em cada um dos períodos nas quais se concretizaram. 
É preciso lembrar que em fins dos anos 1960 e início dos anos 1970 a questão ambiental se apresentava de modo incipiente, embora nos EUA já houvesse uma tradição conservacionista bastante consistente desde fins do século XIX (Fox, 1981). Não obstante o impacto das denúncias do livro de Carson (1964), "Primavera Silenciosa", as questōes políticas que se colocavam naquele período concentravam-se na luta pelos direitos civis dos negros, contra a Guerra do Vietnã e por mudanças comportamentais. Mas no âmbito da cultura do planejamento urbano a figura do "advocacy planner" já era presente e marcou fortemente experiências urbanísticas em que a participação da população foi reivindicada e, em muitos casos, conquistada. É apenas nos remetendo a tais práticas, para as quais o livro de Jane Jacobs, "Morte e Vida das Grandes Cidades", de 1961, foi uma referência importante, que podemos entender a experiência de Oregon analisada a seguir.

\section{THE OREGON EXPERIMENT}

Em meados dos anos 1970, Christopher Alexander propõe para a Universidade de Oregon uma cartilha de seis princípios, em lugar do Plano Diretor convencional com suas premissas tradicionais, com o propósito principal de obter, "desta forma, [...] os meios administrativos necessários para garantir às pessoas o direito ao projeto que escolherem, e o princípio dos processos democráticos de gestão que assegurem um desenvolvimento dinâmico desse direito" (Alexander, 1978, p. 12).

O modelo proposto por Alexander subverte os papéis dos atores envolvidos no planejamento, responsabilizando os usuários, organizados em grupos, pelo projeto dos edifícios, e relegando arquitetos e construtores, ou seja, os técnicos a um papel de suporte e assessoria que consistiria em "fornecer aos membros das equipes de projeto os padrões, os métodos de diagnóstico e toda a ajuda adicional de que precisem para projetar" (p. 42). Quanto aos padróes, por ele definidos "imperativos empíricos" - pois serviriam para "formular problemas concretos e recorrentes em qualquer processo de projeto" (p. 66) tratam-se de princípios gerais de projeto e planejamento que expressam "as condições mínimas necessárias para obter a saúde individual e coletiva de uma comunidade”, conceito a ser construído também comunitariamente.

Para compreendermos o alcance do experimento Oregon é preciso situá-lo no quadro da cultura arquitetônica e urbanística de sua época, em particular nos EUA, marcada pela crise do ideário dos CIAMs (Congressos Internacionais de Arquitetura Moderna), pela retomada de propostas filiadas ao Movimento pela Cidade Jardim, e também pelas concepções urbanísticas de Camillo Sitte. É do início dos anos 1960, nos EUA, a publicação da talvez principal obra crítica de Robert Venturi, em 1963, "Complexity and Contradiction in Architecture" (London: Architectural Press, 1985), e ainda o livro de Walter Creese sobre a cidade jardim na Inglaterra e nos EUA ("Search for Environment. The Garden City: before and after”. Baltimore: The John Hopkins, 1992), bem como a tradução diretamente do original alemão de "Der Städtebau" de Sitte, pelos Collins, acompanhada de uma introdução do casal ("Camillo Sitte and the birth of modern city planning". New York: Random House, 1965) que contribuiu para a reabilitação das ideias de Sitte e sua maior difusão nos EUA. Mas é também da mesma época o livro de Jane Jacobs, "Morte e Vida das Grandes Cidades" (1961), criticando a ausência dos usuários nos planos urbanísticos, bem como o esvaziamento dos espaços públicos abertos, em uma perspectiva crítica dos ideários do urbanismo moderno, alinhada ao ponto de vista do Movimento 
"Townscape" que se irradiava da Inglaterra através das páginas da "Architectural Review" e das concepções de Ian Nairn e Gordon Cullen.

Trata-se também de um período turbulento dos pontos de vista social e político, que culminará nas fortes manifestações estudantis de 1968, tanto na Europa, como nos e Brasil, apesar das especificidades de cada contexto histórico. Nesse sentido, o reclamo que faz Alexander de uma participação efetiva do usuário na formulação dos planos urbanísticos, seja no âmbito de um campus universitário, ou no caso de projetos ou planos urbanísticos com alcance territorial mais amplo, está diretamente associado a demandas políticas de participação da sociedade civil, tanto em cenários autoritários, como no Brasil, quanto em regimes democráticos. Por outro lado, a proposta participativa no campo do planejamento urbano também se vincula ao fracasso das realizações modernistas, marcadamente autorais, que não encontraram receptividade pelos usuários dos espaços concebidos em gabinetes e por profissionais isolados, e que passam a ser progressivamente descaracterizados, quando não se transformam em ilhas de conflito social, como foi o caso do conjunto habitacional "Pruitt-Igoe", construído em 1954/55 em St. Louis, Missouri, sob projeto do arquiteto Minoru Yamasaki, e demolido em 1972/74.

Parece-nos oportuno destacar algumas formulações do texto de Alexander sobre o caso da Universidade de Oregon, onde ele expõe suas reflexôes teóricas e ideias arquitetônicas e de desenho urbano, além de apresentar o plano geral do campus, para que possamos avaliar melhor suas propostas. Já na introdução, ele afirma que seu livro "define um processo que poderia adaptar-se, com pequenas modificações, como plano geral em qualquer comunidade de qualquer lugar do mundo" (p.10). A perspectiva universalista é explícita, ainda que ele especifique que seu experimento se aplicaria a "projetos de comunidades similares", restringindo o alcance de sua proposta. Se nesse quesito Alexander reafirma o universalismo do Movimento Moderno, por outro lado destaca o caráter de processo do plano geral - que nos parece ser o aspecto principal das suas concepçóes no campo do desenho urbano, contrariando as teorias da urbanística moderna que valorizam o plano como produto acabado, mesmo que muitas delas reclamando sua revisão periódica.

Há que se ressaltar também a intenção inovadora de Alexander, preconizando uma ruptura com as teorias estabelecidas, ao considerar seu livro como o terceiro "de uma série que formula uma atitude completamente nova com relação à arquitetura e ao urbanismo" (ibid.), onde também se aproxima do ideário modernista que faz tabula rasa da tradição. Outro aspecto de seu texto que merece ser destacado é o da aplicabilidade do processo proposto em comunidades distintas das de um campus universitário, onde, como ressalta Alexander, temos um único dono-proprietário e um único orçamento centralizado. Em "comunidades similares", como um kibbutz, um hospital ou cooperativa - "em qualquer assentamento no qual o conceito de propriedade privada foi suprimido" - Alexander considera que o processo pode ser aplicado. Ou como ele resume: "propomos aqui um processo que permita às pessoas, sob condiçôes semi-ideais de um orçamento centralizado, cuidarem do meio ambiente por elas mesmas, tendo assim certo controle sobre suas próprias vidas" (Op., cit., p.11). A defesa de uma autonomia a ser conquistada pelo cidadão, em âmbito local, é o que conduz, assim nos parece, Alexander a formular os dois primeiros princípios que, com mais outros quatro, deveriam substituir o plano geral ou diretor. Trata-se dos princípios da "ordem orgânica", onde a ação local é valorizada, enquanto força motriz de um processo, e o da participação, que coloca o poder de decisão sobre o que construir, como e em que local, "nas mãos dos usuários". 
A ideia de participação será assim fundamental no processo de construção do território da Universidade de Oregon e a experiência levada a cabo por Alexander e seu grupo, junto com estudantes e professores, constituiu um marco de referência nas propostas de planejamento de campus universitário a partir do fim dos anos 1970.

\section{THE LEWIS CENTER FOR ENVIRONMENTAL STUDIES}

O Lewis Center foi concebido como uma experiência de educação em engenharia ambiental, arquitetura da paisagem, manejo florestal e arte e ciência do projeto ecológico, com a intenção de melhor capacitar os estudantes para resolver os problemas do século XXI. Tal desafio demandaria mudanças significativas na maneira de pensar os edifícios (e a paisagem circunstante) e seus efeitos em longo prazo (Orr, 2006).

Esta experiência desenvolve-se em um contexto histórico fortemente marcado pela emergência da questão ambiental que, a partir dos anos 1990, adquire proeminência no campo das lutas e reivindicações dos movimentos sociais, impondo ao Estado e as instituições sociais uma nova incumbência, e abrindo para a política um novo domínio; configuram-se novos discursos, desenvolve-se um corpo de normas jurídicas, criam-se agências com o olhar dirigido para um novo campo de intervençôes. É neste novo cenário que se deve ler o projeto do Lewis Center, no âmbito do qual a participação dos estudantes-usuários liga-se diretamente à intenção de se incorporar o ambiental e, sobretudo, a sustentabilidade na concepção desse território do College e, simultaneamente, na formação acadêmica e profissional.

Não cabe aqui discutir as soluções adotadas no projeto, que foram amplamente documentadas por Orr em sua avaliação subsequente. O que importa, para os efeitos da nossa tese, é o processo pelo qual se concretizou a ideia inicial. Esta surgiu da necessidade de contrapor uma alternativa ao padrão de construção do College de Oberlin que, a partir do pós-guerra, teria começado a produzir edifícios baratos, mas de alta manutenção, feios, desconfortáveis e ineficientes, bem como paisagens uniformes, que nada diziam da história das forças geológicas, ecológicas e culturais que contribuíram para moldá-las.

O empreendimento teve início em 1992, com a criação de um grupo de estudantes que se encontraram semanalmente ao longo de um ano para examinar a possibilidade de criar um centro de estudos ambientais. Para tais encontros, os estudantes escolheram o formato de um "júri" que inquiriria arquitetos famosos por sua atuação no campo do projeto ecológico. Naquele ano, os estudantes debateram, efetivamente, com mais de uma dezena de arquitetos diversas possibilidades e, no final do prazo, dispunha-se de um "anteprojeto” ou programa de metas, objetivos, padrões de edificação e possíveis sítios. Aquilo que Orr considera mais importante, porém, é que os participantes haviam aprendido a investigar os custos associados ao ciclo de vida de materiais e edifícios, e a pensar estes últimos como sistemas ecológicos inseridos em sistemas mais abrangentes, e não apenas como coleçôes de componentes isolados.

Autorizada à implantação do Centro, em 1995, sua construção progrediu entre inúmeros percalços criados não apenas pela própria natureza do projeto, independente do normal processo de planejamento do campus, ${ }^{4}$ mas também pelo ceticismo, as críticas e as investidas de pesquisadores e administradores, que contrastava fortemente com o entusiasmo demonstrado pela equipe de projeto e pelos estudantes e docentes nele envolvidos.
4 Se, por um lado, sua independência da burocracia do College permitiu que 0 projeto se desenvolvesse de maneira mais (ecologicamente) criativa, por outro lado, o apoio do reitor não se traduziu necessariamente em uma assistência ativa. 
5 Lyle foi professor de arquitetura e arquitetura da paisagem no California Polytechnic Institute in Pomona e autor do livro Regenerative Design for Sustainable Development (1994). É também fundador do John T. Lyle Center for Regenerative Studies, ao qual foi dado o seu nome em uma homenagem póstuma (1998).

6 A paisagem seria, assim, concebida não como espaço "decorativo" entre edificações, mas como ecossistema projetado para instruir e religar.

7 Environmental Policy Statement for Oberlin College. Disponível em: <http://www. oberlin.edu/sustainability/ about/OCEnvironmentalPolicyMay2004.pdf>. Acesso em: 18 fev. 2010.

8 Aqui entendida como "problemática contemporânea", formulada a partir de um debate inter e multidisciplinar e centrada na discussão das relações entre sociedade e natureza (Carvalho, 2001, p. 166).
Desde o início do empreendimento, Orr tomou a decisão de transformar o projeto em um "exercício educativo sobre como costurar a paisagem, os materiais, a energia, a água e a tecnologia no contexto de um pequeno edifício” (p. 69). Para isso, o processo de projeto foi conduzido de maneira colaborativa pelo departamento de construção do College, por uma equipe de especialistas externos e pelo próprio Programa de Estudos Ambientais. Nas chamadas charrettes - sessōes de projeto, frequentadas por 250 pessoas, entre estudantes e docentes, e coordenadas pelo arquiteto John Tillman Lyle, ${ }^{5}$ os participantes foram estimulados a propor questóes sempre mais abrangentes (como exigia a complexa conjuntura global do final do século XX) e a se aprofundarem nas possibilidades, engajando-se em um processo de aprendizagem que religava a teoria (e o trabalho intelectual) com a prática. Ao final do processo, concordaram-se três princípios básicos: que o edifício não causaria qualquer prejuízo estético (humano ou ecológico) em outros tempos e lugares; que o prédio e a paisagem circunstante se tornariam parte ativa do currículo e não um lugar anônimo para a prática de uma educação descontextualizada; ${ }^{6}$ e que se aplicariam novos instrumentos analíticos para melhor apreender o desempenho do edifício em prazos temporais estendidos.

Em sua retrospectiva do empreendimento, Orr admite que as metas iniciais foram redimensionadas, devido não apenas aos custos, mas também à estrutura decisional adotada, que inibiu a comunicação com outros segmentos da comunidade universitária: "a lacuna entre designers, programa [de estudos ambientais] e college nunca foi efetivamente preenchida" (p. 157), de maneira que a experiência não teria contribuído para a aprendizagem da instituição como um todo. Porém, é possível averiguar que muitas das disposições da Política Ambiental para o College de Oberlin, ${ }^{7}$ elaborada entre 2001 e 2003 por uma comissão especial, inspiram-se nos preceitos e nas práticas de projeto e construção do Adam Lewis Center.

\section{CONSIDERAÇÕES FINAIS}

$\mathrm{Na}$ seção anterior procurou-se destacar a dimensão participativa e suas implicações educacionais em duas experiências de planejamento e projeto de campi universitários. Ambas inserem-se em contextos e processos históricos mais abrangentes. O experimento da Universidade de Oregon representou, de fato, uma reação à incapacidade do Movimento Moderno para acolher as demandas dos usuários na produção do espaço, inclusive universitário. Já o projeto participativo do Lewis Center, além de expressar a adesão de uma comunidade universitária ao mais amplo movimento para a ambientalização da educação superior, vai ao encontro de uma concepção de planejamento que nos anos 1990 seria profundamente influenciada pela emergência da questão ambiental ${ }^{8}$ e pelas diretrizes da Agenda 21, particularmente na ênfase que esta coloca em processos conduzidos localmente, de baixo para cima (bottom-up) (Allmendinger, 2001).

Se o processo empreendido no College de Oberlin já principiou com a premissa de constituir-se em uma experiência educativa que envolveria a participação ativa dos estudantes, do corpo docente e de especialistas no projeto de um edifício sustentável, não se pode desmerecer o conteúdo pedagógico da proposta de Alexander que, evidentemente, enxergava o planejamento como práxis e o campus como um laboratório ideal para a sua realização.

Sua proposta ecoaria para escalas mais amplas, influenciando o planejamento participativo no âmbito da cidade como um todo. A história do campus da Universidade de Oregon nos últimos quase 40 anos foi marcada por essa experiência, sem dúvida bem 
sucedida, que teve continuidade com a incorporação de novas pautas, mas sempre mantendo os mesmos seis princípios formulados por Alexander nos anos 1970.

Das inúmeras questões que o Experimento de Oregon suscita até nossos dias, e contribui para pensarmos os territórios universitários contemporâneos, quando o paradigma da sustentabilidade se impõe, sublinhamos aqui o da relação da universidade com a cidade, ou dos territórios universitários com a multiplicidade de territórios que constitui uma cidade e as fronteiras nas quais se manifesta a tensão apontada por Bender.

Se pensarmos o campus não mais como um enclave na cidade, quando não exilado no campo, devemos a partir de Alexander cogitar a participação na sua construção não como uma prática apenas da comunidade universitária, mas também dos seus vizinhos e mesmo do conjunto dos cidadãos. É nessa perspectiva que as atuais demandas de busca por níveis de sustentabilidade devem se apoiar, fazendo da participação dos atores - e não apenas usuários - um elemento decisivo para a formulação e implantação de um processo de construção do campus, que seja também da cidade.

\section{REFERÊNCIAS BIBLIOGRÁFICAS}

ALEXANDER, C.; SILVERSTEIN, M.; ANGEL, S.; ISHIKAWA, S.; ABRAMS, D. Urbanismo y Participación. El caso de la Universidad de Oregón - The Oregon Experiment. Barcelona: Gustavo Gili, 1978.

ALLMENDINGER, P. Planning in post-modern times. London: Routledge, 2001.

BENDER, T. The University and the city: from medieval origins to the present. New York: Oxford University Press, 1988.

BOMENY, H. A Reforma Universitária de 1968, 25 anos depois. S.d. Disponível em: $<$ http://www.anpocs.org.br/portal/publicacoes/rbcs_00_26/rbcs26_04.htm>. Acesso em: 13 abr. 2010.

CAMPBELL, S. Green cities, growing cities, just cities? Urban planning and the contradictions of sustainable development. Journal of the American Planning Association, v. 3, n. 62, p. 296-312, 1996.

CARSON, R. Primavera Silenciosa. São Paulo: Melhoramentos, 1964.

CARVALHO, I. C. M. A invenção ecológica: narrativas e trajetórias da educação ambiental no Brasil. Porto Alegre: Editora da Universidade/UFRGS, 2001.

FOUTO, A. R. F. O papel das universidades rumo ao desenvolvimento sustentável: das relações internacionais às práticas locais. Mar. 2002. Disponível em: <http://campusverde/ pt>. Acesso em: 03 jun. 2006.

FOX, S. The American Conservation Movement. John Muir and his legacy. Boston: The University of Wisconsin Press, 1981.

GLASSER, H. "Minding the gap: the role of social learning in linking our stated desire for a more sustainable world to our everyday actions and policies". In: WALS, A. E. J. (Ed.). Social learning: towards a sustainable world. Wageningen: Wageningen Academic Publishers, 2007. p. 35-62.

JACOBS, J. Morte e vida de grandes cidades. São Paulo: Martins Fontes, 2000.

MACEDO, A. C. O desenho do campus universitário. Projeto, São Paulo, n. 93, p. 96-98, nov. 1986a.

O meio ambiente do campus universitário e seu projeto. Projeto, São Paulo, n. 94, p. 104-106, dez. 1986b.
Carlos Roberto Monteiro

de Andrade é arquiteto, urbanista e sociólogo; professor do IAUUSP; mestre e doutor pela FAU-USP; pósdoutorado junto ao Politécnico de Milão. E-mail: candrade@sc.usp.br

Alessandra Pavesi é ecóloga; pesquisadora associada no Departamento de Metodologia de Ensino da UFSCar; mestre em Ciências da Engenharia Ambiental pela EESC-USP; doutora em Educação pela UFSCar; pós-doutorado no IAU-USP. E-mail: sandrapavesi@gmail. com

Artigo recebido em março de 2012 e aprovado para publicação em junho de 2012. 
PAVESI, A.; FREITAS, D. A problemática socioambiental na formação do arquiteto: perspectivas e desafios apontados por um estudo do currículo de um curso de arquitetura e urbanismo. Revista Risco, n. 7, p. 107-122, 2008.

ORR, D. W. Design on the edge: the making of a high-performance building. Cambridge: The MIT Press, 2006.

SACHS, I. "Estratégias de transição para o século XXI". In: BURSZTYN, M. (Org.). Para pensar o desenvolvimento sustentável. São Paulo: Brasiliense, 1994. p. 29-56.

SILVA, T. T. O que produz e o que reproduz em educação. Porto Alegre: Artes Médicas, 1992.

SOUZA, M. P. S. Instrumentos de Gestão Ambiental: fundamentos e práticas. São Carlos: Riani Costa, 2000.

WRIGHT, T. Definitions and Frameworks for Environmental Sustainability in Higher Education. International Journal of Sustainability in Higher Education, v. 3, n. 3, p. 203220, 2002.

A B S T R A C T This paper discusses two campus planning experiences carried out in the USA with the active participation of the academic communities: "The Oregon Experiment", promoted by the University of Oregon in 1970, and the design of the Lewis Center for Environmental Studies at Oberlin College (Ohio), developed twenty years later, in a decade strongly characterized by the rise of environmental concerns. Despite being oriented by different theoretical backgrounds in different moments, the two experiences have common features. The article seeks to highlight these common aspects; the understanding of participation as a praxis and using the campus as an ideal laboratory for its achievement.

K E Y W O R D S Planning; campus; participation; education; sustainability. 